\title{
Lithium Diisobutylpiperidinohydroaluminate (LDBPA) as a Mild and Efficient Reducing Agent for the Conversion of Ester to Aldehyde
}

\author{
Jin Hee Ahn, Jeong In Song, Jeong Eun Ahn, and Duk Keun An* \\ Department of Chemistry, Kangwon National Lniversity, Chunchon 200-701, Korea. "E-mail: akanakangwonackr

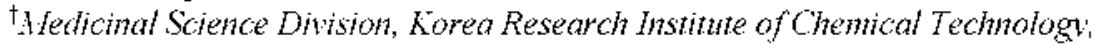 \\ loo Jang-Dong. Itisung. Daejeon 305-600, Norea \\ Received Jahuary 13, 2005
}

Key Words : Lithium diisobutțlpiperidinohydroaluminate (LDBPA). Diisobutylaluminium hydride. Aldehỵde. Partial reduction. Piperidine

Partial reduction of ester to aldehyde is very efficient and reliable procedure in organic synthesis. and a number of reducing agents for this have been reported. ${ }^{1-5}$ Anlong them. diisobutylaluninium hydride (DIBAH) which is commercially available is used as one of the most popular reducing agent. However. to achieve the partial reduction successfully. this reagent requires very low temperature $\left(-78^{\circ} \mathrm{C}\right)$. Recently, we $\mathrm{e}^{\text {5a-b }}$ reported the synthesis of aldehyde from ester with sodium diethylpiperidinohydroaluminate (SDPA) at $0^{\circ} \mathrm{C}$. However. sodium diethyldihydroaluminate which is the precursor for synthesis of SDPA is not conmercially available. In the course of our program for developing new selective reducing agent, we found that lithium diisobutyldialkylaminohydroalumonates prepared from DIBAH smoothly reduced esters to aldehydes at $0^{\circ} \mathrm{C}$, although it has been reported that the reduction of esters to aldehydes using aluminium hydride derivatives having n-buty $\mathrm{l}^{6}$ or alkoxy ${ }^{7}$ groups obtained from DIBAH has been not successful. We hereby report such conversion using these new mild and efficient reducing agents.

Scheme 1 outlines the preparation of lithium diisobutyl- dialkylaminolyydroalumonates from DIBAH. Thus. when an equimolar amount of lithium dialkylamides with DIBAH was reacted in THF at $0^{\circ} \mathrm{C}$ or room temperature. these reagents were obtained quantitatively. Next, we examined partial reduction of esters to aldehydes using these hydride reagents in THF at $0^{\circ} \mathrm{C}$. Of these hydrides examined. we found that lithium diisobutylpiperidinolyydroaluminate (LDBPA) ${ }^{8}$ provided the best results. So we have applied this LDBPA for the synthesis of aldehydes from the various esters at $0^{\circ} \mathrm{C}$. The results for representative esters are summarized in Table 1.

As shown in Table 1 , ethyl benzoate was smoothly reduced to produce benzaldehyde in $83 \%$ yield (entry 1 ). ${ }^{9}$ Under identical conditions, the reduction with DIBAH itself provided only benzyl alcohol (entry 2). Similarly. reduction of isopropyl benzoate afforded benzaldehyde in $81 \%$ yield (entry 3). The case of $t$-butyl benzoate under the same condition proceeded somewhat slowly (entries 4-6). It is attributable to the bulky size of $t$-butyl group. Also, reduction of other aromatic esters, such as phenyl benzoate, methỵl 3.4-dimethosỵbenzoate and methyl 3-chlorobenzoate,

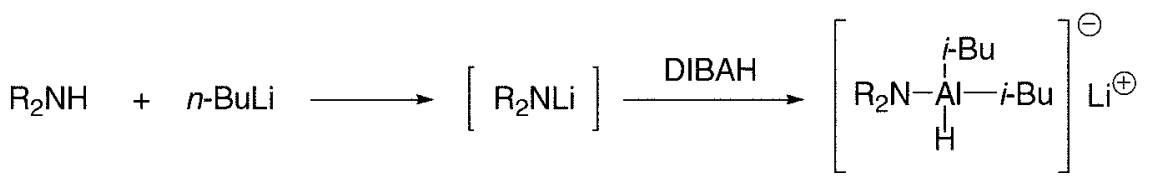$$
[\underset{\substack{\mathrm{N}-\mathrm{Al}-\mathrm{B}-\mathrm{Bu} \\ \mathrm{H}}}{\mathrm{H}}]_{\mathrm{Li}}^{\oplus}
$$

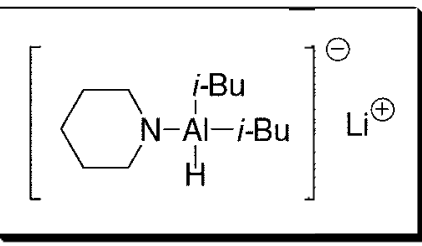

LDBPA

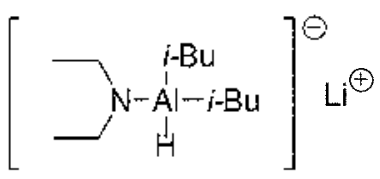

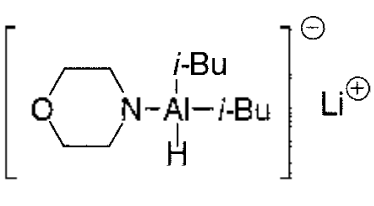

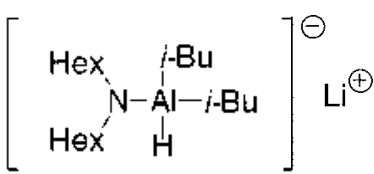

Scheme 1. Preparation of lithiun disobutyldialkylaninohydroaluninates. 
Table 1. Yields of aldehydes in the reduction of representative esters with LDBPA at $0^{\circ} \mathrm{C}$

\begin{tabular}{|c|c|c|c|c|c|}
\hline \multirow{2}{*}{ entry } & \multirow{2}{*}{ compound } & \multirow{2}{*}{ product } & \multicolumn{2}{|c|}{ reaction condition } & \multirow{2}{*}{ yield $(\%)$} \\
\hline & & & $\mathrm{H}^{-} / \mathrm{ester}$ & time (h) & \\
\hline 1 & ethyl benzoate & benzaldehyde & 1.5 & 1 & 83 \\
\hline 2 & & & (1.5) & (1) & $(0)^{b}$ \\
\hline 3 & isopropyl benzoate & benzaldelnyde & 1.5 & 1 & 81 \\
\hline 4 & t-butyl benzoate & benzaldelnyde & 1.5 & 1 & 57 \\
\hline 5 & & & 2.0 & 1 & 69 \\
\hline 6 & & & 2.5 & 1 & 71 \\
\hline 7 & phenyl benzoate & benzaldehyde & 1.5 & 1 & 67 \\
\hline 8 & methyl 3,4-dimethoxybenzoate & 3,4-dimethoxybenzaldehyde & 1.5 & 1 & 67 \\
\hline 9 & methy-3-chlorobenzoate & 3-chlorobenzaldehyde & 1.5 & 1 & 83 \\
\hline 10 & ethyl caproate & caproaldehyde & 2.0 & 1 & 66 \\
\hline 11 & isopropyl caproate & caproaldehyde & 2.0 & 1 & 77 \\
\hline 12 & ethyl undecanoate & undecanal & 2.0 & 1 & 54 \\
\hline 13 & ethyl cimamate & cimamyl aldehyde & 2.0 & 1 & 47 \\
\hline
\end{tabular}

"Yields were detennined by GC. "Yields obtained by DIBAH alone are shown in parenthesis.

gave the corresponding aldehydes in moderate yields (entries 7-9). Reduction of aliphatic esters. namely ethyl caproate. isopropyl caproate and ethyl undecanoate, and an $\alpha, \beta$ unsaturated ester, ethyl cinnamate, provided product aldehyde with lower yields than aromatic analogies (entries 10-13).

Although the mechanisn of this reduction is not clear. we propose it as follow. Reaction of eqimolar esters and LDBPA rapidly forms two unstable intermediates 1 and 2 by the attack of hydride or piperidyl group on $s p^{2}$ carbon of ester, and these are quickly transforned into a more stable intermediate. $\alpha$-piperidyl alkoxoaluminate 3 , by the rearrangement involving migration of piperidyl group or hydride (Scheme 2).

In summary. we have prepared a series of lithium

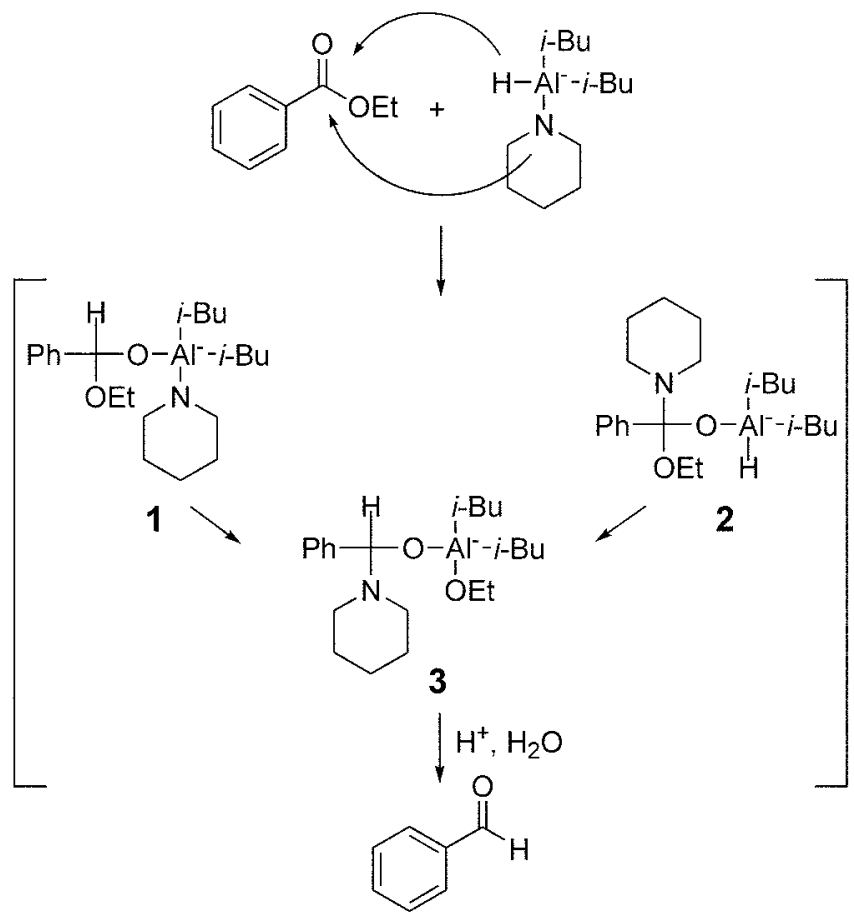

Scheme 2 diisobuty ldialkylaminolyydroaluminates by reacting DIBAH with lithium dialkylamides. Among them. LDBPA was most effective for partial reduction of esters to aldelydes in moderate to good yields at $0^{\circ} \mathrm{C}$. This reagent proved to be one of effective partial reducing agents for preparation of esters to aldelydes. Therefore. LDBPA is believed to be an alternative reagent for the synthesis of aldehydes from esters instead of DIBAH.

Acknowledgment. This work was supported by Kangwon National University.

\section{References and Notes}

1. Zakharkin. L. I.: Khorlina. I. M. Terahedron Lett. 1962.619.

2. Kiml. S. H.: Kiml. J. H.: Yoon. N. M. Bull. Korean Chem. Soc. 1989. 10. 117 .

3. Weissman, P. M.; Brown, H. C. J. Org. Chem. 1966, 31, 283.

4. (a) Muraki. M; Mukaiyama. T. Chem. Lett. 1975.215 , (b) Cha. J. S.; Kwon, S. S. J. Org. Chem. 1987, $55,5486$.

5. (a) Yoon. N. M.: Ahn. T. H.: Ant. D. K.: Shon1. Y. S. J. Org Chent 1993. 58. 1941 (b) Yoon1. N. M.: Shon. Y. S.: Ahn. J. H.: An1. J. W. Bull. Korew Chent Soc. 1993. 11. 522.

6. Kim. S.: Ahn, K. H. J. Org. Chem. 1984, 19. 1717

7. Cha. J. S.; Kwon, S. Y.; Kim, J. M.: Kwon. O. O.: Lee, K. W. Bull. Korean Chem. Soc. 1999. 20,737.

8. The following procedure for the preparation of LDBPA is illustrative. To a solution of piperidine $(0.99 \mathrm{~mL} .10 \mathrm{mmol})$ in THF $(2.76 \mathrm{~mL})$ was added $n$-butyllithium $(6.25 \mathrm{~mL} .1 .6 \mathrm{M}$ in hexane, $10 \mathrm{mmol}$ ) at $0{ }^{\circ} \mathrm{C}$. After being stirred for $1 \mathrm{~h}$ at room temperature, to this added dropwise DIBAH $(10 \mathrm{~mL} .1 .0 \mathrm{M}$ in hexane, $10 \mathrm{mmol}$ ) at $0^{\circ} \mathrm{C}$ and the mixture was stirred for $1 \mathrm{~h}$ at room temperature. The result was clear colorless solution.

9. The following procedure for the reduction of ethyl berizoate with LDBPA is representative. To a solution of ethyl benzoate (0.07 $\mathrm{mL} .0 .5 \mathrm{mmol}$ ) in THF (5 mL) containing naphthalene as an intenal standard was added LDBPA (1.5 mL. $0.5 \mathrm{M}$ in THFhexane) at $0^{\circ} \mathrm{C}$. After 3 h, the reaction mixture was hydrolyzed with $5 \mathrm{~mL}$ of $\mathrm{I} \mathrm{N} \mathrm{HCl}(a q)$ and the product was extracted with 10 $\mathrm{mL}$ of diethyl ether. The ether layer was dried over anhydrous potassium carbonate. GC analysis showed an $83^{\circ} \circ$ yield of benzaldehyde. 